\title{
Sedentary behaviour and adiposity in youth: a systematic review of reviews and analysis of causality
}

\author{
Stuart J.H. Biddle ${ }^{1,2^{*}}$, Enrique García Bengoechea ${ }^{1,3}$ and Glen Wiesner ${ }^{1}$
}

\begin{abstract}
Background: Sedentary behaviour (sitting time) has becoming a very popular topic for research and translation since early studies on TV viewing in children in the 1980s. The most studied area for sedentary behaviour health outcomes has been adiposity in young people. However, the literature is replete with inconsistencies.
\end{abstract}

Methods: We conducted a systematic review of systematic reviews and meta-analyses to provide a comprehensive analysis of evidence and state-of-the-art synthesis on whether sedentary behaviours are associated with adiposity in young people, and to what extent any association can be considered 'causal'. Searches yielded 29 systematic reviews of over 450 separate papers. We analysed results by observational (cross-sectional and longitudinal) and intervention designs.

Results: Small associations were reported for screen time and adiposity from cross-sectional evidence, but associations were less consistent from longitudinal studies. Studies using objective accelerometer measures of sedentary behaviour yielded null associations. Most studies assessed BMI/BMI-z. Interventions to reduce sedentary behaviour produced modest effects for weight status and adiposity. Accounting for effects from sedentary behaviour reduction alone is difficult as many interventions included additional changes in behaviour, such as physical activity and dietary intake. Analysis of causality guided by the classic Bradford Hill criteria concluded that there is no evidence for a causal association between sedentary behaviour and adiposity in youth, although a small dose-response association exists.

Conclusions: Associations between sedentary behaviour and adiposity in children and adolescents are small to very small and there is little to no evidence that this association is causal. This remains a complex field with different exposure and outcome measures and research designs. But claims for 'clear' associations between sedentary behaviour and adiposity in youth, and certainly for causality, are premature or misguided.

Keywords: Sedentary, Screen time, Television, Children, Adolescents, Obesity, Weight status, BMI

\section{Background}

Sedentary behaviour has been defined as low energy sitting (or reclining) during waking hours [1], thus excluding sleep or seated exercise. It is, essentially, 'sitting time' rather than 'lack of exercise'. Research in this field has expanded exponentially since the early 2000 s. Sedentary

\footnotetext{
* Correspondence: stuart.biddle@usq.edu.au

${ }^{1}$ Institute of Sport, Exercise \& Active Living, Victoria University, Melbourne, Australia

${ }^{2}$ Institute for Resilient Regions, University of Southern Queensland, Education City, 37 Sinnathamby Boulevard, Springfield Central, QLD 4300, Australia

Full list of author information is available at the end of the article
}

behaviour as a research topic has emerged on the basis of having shown high rates of sitting in contemporary society and associations with deleterious health outcomes [2]. Such associations have been claimed to be somewhat statistically independent of participation in moderate-to-vigorous physical activity (MVPA) [3, 4], and sedentary behaviour in adults has shown reasonable evidence of a causal relationship with all-cause mortality [5]. However, emerging evidence is also suggestive that the negative health effects of sedentary behaviour are more likely in those who are not sufficiently physically active [6]. 
Evidence on the health effects of sedentary behaviour started to build in a systematic way with studies from the 1980s on television (TV) viewing in children and adolescents. In 1985, Dietz and Gortmaker published a paper in which they suggested we may be 'fattening our children at the TV set' [7]. In analyses of data from over 6,500 young people from the National Health Examination Survey in the USA, they concluded not only that an association existed between TV viewing and adiposity, both cross-sectionally and longitudinally, but that their evidence "fulfils the criteria necessary to establish a causal association" (p. 811). Interestingly, they also state that TV viewing "only accounts for a small proportion of the variance of childhood obesity" (p. 811). Moreover, while claiming evidence for a dose-response relationship, their longitudinal data, shown in histograms, illustrates that more than five hours per day of TV viewing had the highest prevalence of obesity, whereas lower levels were less obviously indicative of a dose-response. This is suggestive of a stepped or threshold effect rather than a linear effect, the latter being shown a little more clearly for 'superobesity' (at or above $95^{\text {th }}$ percentile for triceps skinfold). The study by Dietz and Gortmaker did not control for dietary intake or physical activity.

Overall, Dietz and Gortmaker's [7] study was an important start in recognising that one specific sedentary behaviour - TV viewing - might be a risk factor for obesity in young people. However, at the same time, some of the conclusions may have been premature on the assessment of causality.

Another key study was provided by Hancox et al. [8] in their investigation of over 1,000 children from New Zealand. They found that hours of weekday TV viewing between the ages of 5-15 years were associated with higher body mass index (BMI) some 10 years later. However, they also found similar associations for smoking, low fitness, and raised cholesterol. The data on smoking suggests that poor health behaviours may be clustering together rather than necessarily causing each other. Nevertheless, Hancox et al's study provided more convincing evidence that TV viewing in childhood might be associated, prospectively, with adiposity later in life.

The first meta-analysis investigating associations between sedentary behaviour, in the form of TV viewing, and adiposity in youth was reported by Marshall et al. [9]. Reporting a fully corrected effect size (Pearson $r$ ) of 0.066 , they concluded that while this was statistically significant, the very small amount of variance in adiposity explained by the amount of TV viewing "calls into question the clinical relevance" (p. 1241) of this association. Moreover, and especially when a wider range of sedentary behaviours is accounted for, opinions continue to be divided. For example, due to the use of cross-sectional designs and the potential confounding factors of physical activity and diet, Saelens [10] stated that the "conclusions regarding the relationship between sedentary behaviour and adiposity in youth are necessarily tentative" (p. 221). While Saelens was referring to a range of sedentary behaviours, most of the studies he reviewed concerned screen time, with nearly all including TV viewing. Nonetheless, several organisations have supported the view that TV viewing is a problematic behaviour from the stand point of obesity risk, including statements from the Australian College of Paediatrics [11] and an expert group of the American College of Sports Medicine [12].

Since the 1980s, but mainly from the mid-2000s, there has been expanding interest in whether sedentary behaviour is associated with negative health outcomes in both adults and young people. Given the developments in technology during this period, research has widened the focus from TV viewing to 'screen time' (TV and computers), and to other sedentary behaviours, including sitting at school, in a car, and pursuing other leisure interests. At the same time, technology has enabled researchers to assess the quantity and patterning of sedentary behaviour using wearable devices that assess either lack of movement or postural allocation. This has allowed for more diverse assessments alongside traditional self-reporting of time, behaviour, and context. Evidence seems to suggest that measures from wearable technology - so called 'objective measures' - yield much more inconclusive evidence for an association between sedentary behaviour and adiposity in youth, or even no association at all [13].

Key potential confounders of any relationship between sedentary behaviour and adiposity are physical activity and dietary intake, and with adolescents, maturational status. In addition, some have indicated that sleep may also play a role $[14,15]$. Sedentary behaviours have sometimes been proposed to displace time in more active pursuits. Given that at any specific time, sitting precludes light, moderate or vigorous physical activity, this seems a logical assumption. However, the real issue is whether certain sedentary behaviours, or large amounts of sedentary behaviour, preclude physical activity at other times of the day. Given $24 \mathrm{~h}$ in a day, it is feasible that large amounts of both sitting and moving are possible. That is, they could co-exist over time. To date, typical findings suggest that less MVPA is associated with greater levels of sedentary behaviours, but this relationship is usually small. The association with light physical activity (e.g. standing and light ambulation) is large because this is where sitting time tends to get displaced to and from and the two behaviours are somewhat interdependent $[16,17]$.

Certain sedentary behaviours may also be associated with changed dietary patterns. For example, eating in 
front of the TV may trigger greater snacking or consumption of unhealthy foods prompted by advertisements. Pearson and Biddle [18] conducted a systematic review across all ages and concluded that greater sedentary behaviour, often studied as screen time, showed a clear association with unhealthy dietary intake, including higher consumption of energy-dense snacks and less consumption of fruits and vegetables. For children, "TV viewing was consistently inversely associated with fruit and vegetable consumption and positively associated with consumption of energy-dense snacks and drinks, total energy intake, and fast foods" (p. 185). Studies testing for associations between sedentary behaviour and adiposity, therefore, ideally need to control for levels of physical activity (i.e., MVPA), dietary intake, and possibly sleep.

A great deal of the literature has comprised observational and cross-sectional studies. To advance this field, we need to better understand to what extent sedentary behaviour might be causally associated with adiposity in youth. Claims of causality have been made (see earlier), but these have not been based on established criteria such as those proposed by Hill [19, 20]. Nine factors were listed by Hill ('Bradford Hill criteria'): strength of association, consistency, specificity, temporality, biological gradient (dose-response), (biological) plausibility, coherence, experimental evidence, and analogy. For sedentary behaviour and adiposity in young people, the key issues that can be assessed using the findings from the current review of reviews are strength of association, consistency, specificity, temporality, coherence and biological plausibility, dose-response, and experimental evidence (see Table 3 in Results for definitions).

Given that sedentary behaviour is highly prevalent in modern society, that such behaviours (especially screen based) are rapidly evolving and changing, and obesity is a key health issue, it is important to try to resolve the inconsistencies evident in the literature on the association between sedentary behaviour and adiposity in young people. To this end, we conducted a review of reviews and an analysis of whether any such association can be judged as causal. The following research questions will be addressed:

1. Is there an association between sedentary behaviour and adiposity in young people?

2. If so, does this association differ by type of sedentary behaviour and type of marker of adiposity?

3. Do MVPA or dietary intake moderate this association?

4. To what extent can any association between sedentary behaviour and adiposity be considered causal when using key criteria proposed by Hill [19]?

Given the plethora of evidence available on the current topic, we conducted a review of reviews [21]. Such a method allows for a summary of evidence from multiple reviews that focus on the same but inevitably overlapping research questions, often using multiple methods and measures. In addition, it allows for a comparison of findings and to resolve discrepancies in conclusions that might exist across reviews. It also allows for an analysis of mediators and moderators of a relationship [21].

\section{Method}

PubMed and Scopus were searched up to July 2016 to identify systematic reviews and meta-analyses examining relationships between sedentary behaviours and markers of weight status/adiposity in children and adolescents. Groups of thesaurus terms and free terms for sedentary behaviour (e.g. sedentary, sitting, TV viewing), markers of weight status (e.g. adiposity, BMI, obesity), age group (e.g. children, youth), and publication type (e.g. metaanalysis, synthesis) were used. This resulted in the following example search: title-abs-key(sedentary OR sitting OR "watching TV" OR "TV watching" OR "viewing TV" OR "TV viewing" OR "television watching" OR "watching television" OR "television viewing" OR "viewing television" OR "screen time" OR "computer use") AND title-abs-key(weight OR obesity OR "body mass" OR BMI OR overweight OR adiposity OR fatness OR "body composition") AND title-abs-key(children OR childhood OR youth OR adolescen* OR "young people") AND title-abs-key(review OR meta-analysis OR metaregression OR synthesis). Additional reviews and metaanalyses were identified by manually checking the reference lists of included papers and searching the authors' own literature databases.

To be included in the present analysis, review papers had to meet the following criteria: 1) population to include children or adolescents under the age of 19 years; 2) include at least one measure of sedentary behaviour; 3) report associations of sedentary behaviours with a measure of weight status or adiposity; and, 4) be a systematic review or a meta-analysis. Reviews summarizing or quantifying the evidence for associations could be based on subjective (e.g. questionnaires) or 'objective' (wearable) measures of sedentary behaviour (e.g. accelerometers, inclinometers), as well as overall sedentary behaviour or setting-specific sedentary behaviour (e.g. TV viewing time). Reviews or meta-analyses including measures of sedentary behaviour that were a combination measure of sedentary behaviour and physical activity, such as categorical measures with sedentary as the least active category, were excluded. We also excluded preschool children (usually less than 5 years of age) on the basis that their environmental and social context differs considerably from those attending school.

Only full text peer reviewed articles written in English were considered for inclusion. Titles and abstracts of the 
identified references were reviewed by two people to exclude articles out of scope. Subsequently, two reviewers independently reviewed the full text of all potentially relevant references for eligibility using a standardized 'in-out' form. Disagreements between these reviewers were discussed with a third reviewer and a consensus decision was reached.

Data extraction was conducted by three researchers; one checked all reviews and disagreements were settled by consensus. Where reviews covered multiple age groups, intervention types, behavioural measures or health outcomes, the extracted data were based on and limited to key inclusion criteria stated above.

The methodological quality of each systematic review was assessed using the 'Assessment of Multiple Systematic Reviews' (AMSTAR) rating scale [22]. AMSTAR contains 11-items to appraise the methodological aspects of reviews with items scored as "Yes", "No", "Can't Answer" or "Not Applicable". For AMSTAR items, see footnote to Table 2. The item on conflict of interest (COI) requires that the systematic review and all primary studies be assessed. We modified this item to assess only the review itself. PRISMA does not require a COI assessment for each primary study. Each of the included systematic reviews was assessed by one researcher, $30 \%$ by two researchers, and all assessments were discussed and agreed by three researchers.

Findings will be summarised as follows. First, results will be presented from reviews focussed on observational cross-sectional and longitudinal studies. Second, evidence from intervention studies will be presented. In both sets of results, data will be separated by self-report and objectively assessed sedentary behaviour. For selfreported behaviours, the type of behaviour will be specified. Where possible, outcome measures will be differentiated, such as reporting results for BMI or waist circumference. An appraisal of the causal nature of any relationships will then be assessed (e.g., strength of association). Emphasis will be given to systematic reviews that are more recent, larger, and have a higher AMSTAR rating.

One key aspect of interpretation of findings is regarding the strength of association. This is also dealt with in more detail later under our analysis of causality. In interpreting strength of associations or effects, we have drawn on multiple sources, including the interpretation by the original review paper authors, as well as the interpretation of others, such as Cohen [23] and Rosenthal [24].

\section{Results}

\section{Characteristics of systematic reviews}

Searches led to 51 full papers being assessed for eligibility, and 29 systematic reviews were selected for research synthesis (see the PRISMA flowchart in Fig. 1). Two of the main reasons for rejecting full papers at this stage were not being a systematic review and not having an association reported between sedentary behaviour and weight status.

Data from all reviews were extracted and summarized in Table 1. Nineteen reviews included data from primary studies utilizing observational methods [cross sectional $(n=4)$ [25-27], longitudinal $(n=5)$ [28-32], or both $(n$ $=10)[9,33-41]]$. Four of these reviews also included data from intervention studies, with three only analyzing a single intervention $[9,40,42]$, and one review including four. There were 10 reviews that focused on intervention studies [43-52]. Nearly all reviews included children and adolescents up to the age of 18 years, although not all age ranges were identical. Where possible, we extracted data and drew conclusions only from the appropriate age range (i.e. 6-18 years). The number of studies included in the systematic reviews varied greatly, ranging from 3 to 162 observational studies and 4 to 67 intervention studies. We estimated that the 29 reviews included 467 primary study papers, although due to poor reporting and errors in citations, this figure is not exact. One large review did not provide sufficient detail to list all primary studies used [49].

Given that the field of research on sedentary behaviour and health outcomes is relatively new, the majority of reviews were published after 2011. Of the 19 focussing on observational studies, 15 (79\%) were published between 2012 and 2016. The first reviews to include these topics were published in 2004, including a meta-analysis of associations between body fat and both TV viewing and computer use [9], and a review of correlates of TV viewing [38]. Of the reviews addressing the effectiveness of interventions, 7 of the 10 were published between 2011 and 2016. Overall, 4 of the observational reviews and 7 of the intervention reviews included a meta-analysis, or at least some calculation of effect sizes. Ten reviews included an assessment of study quality or risk of bias.

A key issue to address is the assessment of both exposure and outcome variables. For the measurement of sedentary behaviour, 17 reviews synthesised studies that had only self-reported behaviour, 4 for only objective measures [29, 31, 34, 37], and 8 reviews included both types of assessment. All reviews addressing self-reported sedentary behaviour included measures of screen time (TV viewing and computer time either singly or combined). Very few additional self-reported sedentary behaviours were assessed. For the use of objective wearable technology, all reviews relied on the Actigraph accelerometer, thus reporting on 'low or lack of movement' rather than sitting per se. A variety of outcome measures of weight status and adiposity were reported, with nearly all reviews reporting on BMI. 


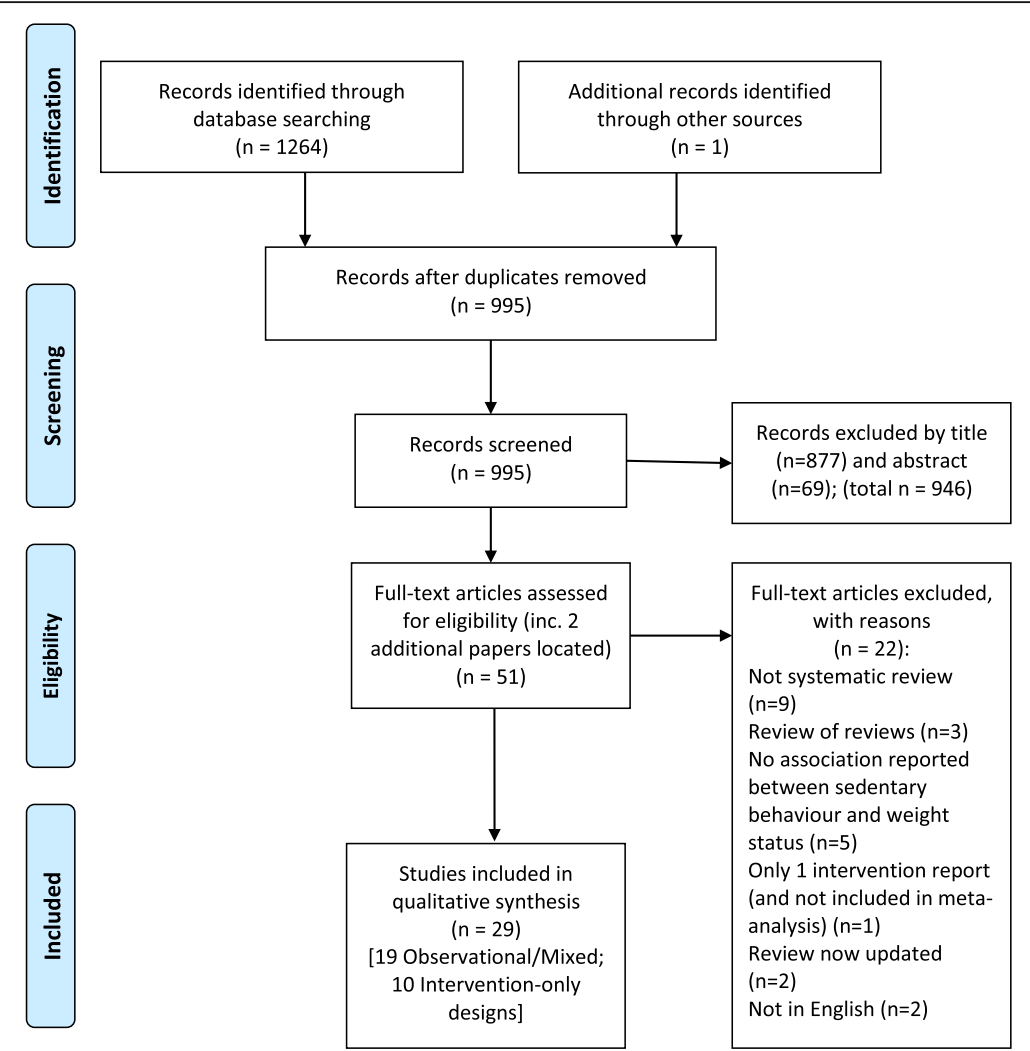

Fig. 1 PRISMA flow diagram for selection of systematic reviews

Table 2 summarises the AMSTAR ratings. From a total possible score of 11 , the majority $(66 \%)$ of reviews received a rating of at least 5 . The ratings were partly a function of date of publication with $60 \%$ of those rated 4 or below and only $11 \%$ of those rated 5 or above being published prior to 2010. This is likely due to the more recent development and adoption of review guidelines (e.g. PRISMA).

\section{Evidence for an association between sedentary behaviour and adiposity from observational studies}

For self-reported sedentary behaviour, all reviews addressed TV and screen time. All 7 reviews synthesising associations with TV viewing alone showed a positive relationship (i.e. greater TV viewing time associated with indicators of greater adiposity). The first review of correlates of TV viewing in youth showed that while greater TV viewing was associated with higher body weight, it was not associated with body fat [38]. Some of these associations are small, or very small, and this will be discussed in the analysis of causality.

Similar results were found for assessments of screen time, although all include TV viewing alongside video game/computer use. When analysing data from reviews that report results separately for computer use, however, the picture is less clear. Two reviews report no association $[9,32]$, while one review shows a clear association for longitudinal studies but mixed results for cross-sectional [41].

Results from longitudinal studies show some differences from those using cross-sectional designs. For example, van Ekris et al.'s [32] review of just prospective studies concluded that there was 'strong' evidence for an association with 'overweight and obesity' for TV viewing ('strong' was defined as two or more high quality studies showing consistent findings), but 'insufficient' evidence for TV viewing and other markers of adiposity. Similarly, they concluded 'strong' evidence for an association between screen time and BMI, but 'insufficient' for other measures of adiposity. However, a large number of cross-sectional studies reviewed by Carson et al. [33], concluded in favour of an association for adiposity with $\mathrm{TV}$ viewing and screen time.

All nine reviews assessing the association between objectively assessed 'total' sedentary time were consistent in their conclusion in showing a null or inconsistent association with adiposity. This was true for both crosssectional and longitudinal designs. For example, Cliff et al.'s meta-analytic review [34] showed no association for longitudinal studies and a significant but very small association $(r=0.07)$, with high heterogeneity, for crosssectional studies. Similarly, van Ekris et al. [32] 


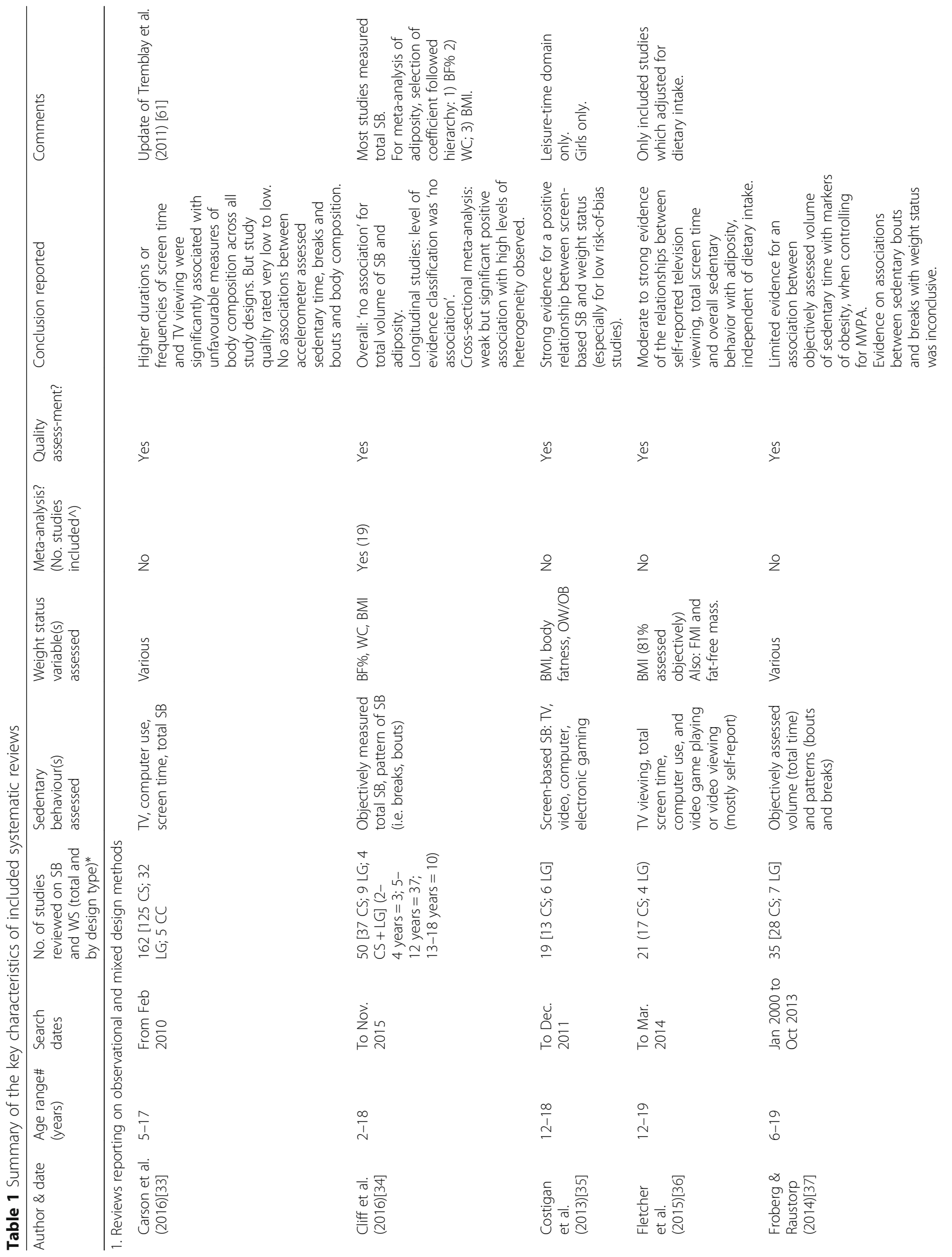




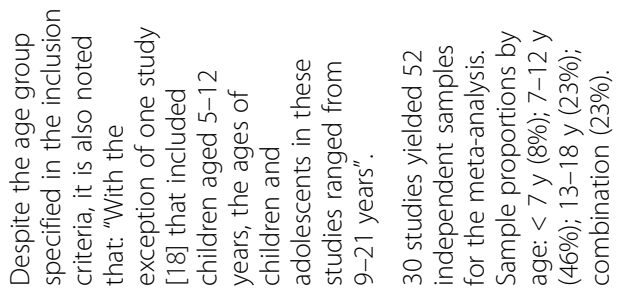

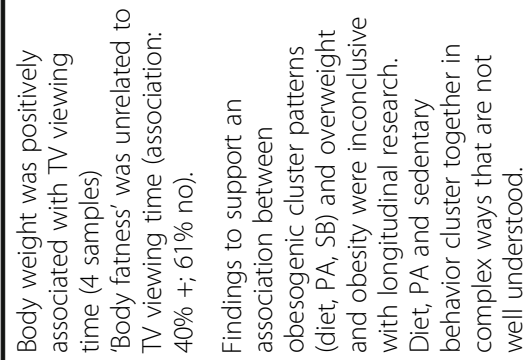

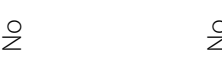

울

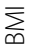

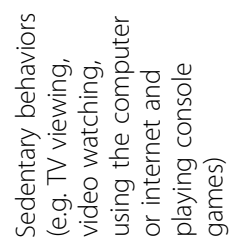

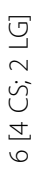

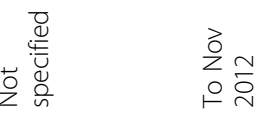

$\stackrel{\infty}{i}_{i}^{\infty}$

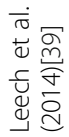

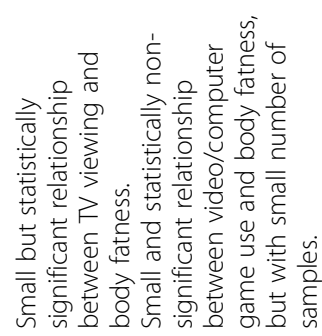

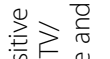

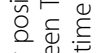

完致离

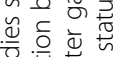

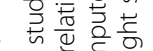

告记

운

$\stackrel{0}{0}$
$\stackrel{y}{y}$

울

2

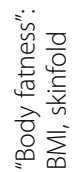

$\stackrel{\infty}{0}$

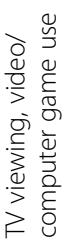

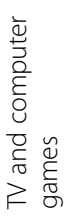

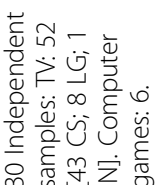

$\stackrel{i}{i}$

$\frac{\infty}{m}$

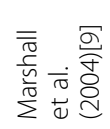

2

$\simeq$

응

독

$\frac{\infty}{b}$

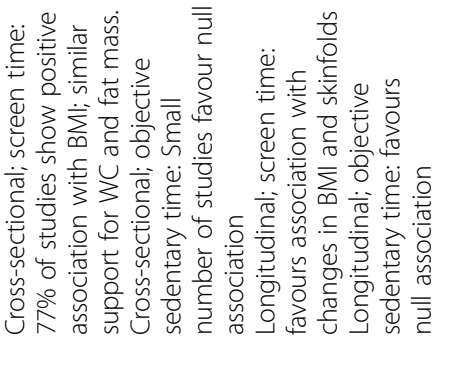

$\stackrel{\frac{n}{0}}{\frac{0}{\bar{m}}}$

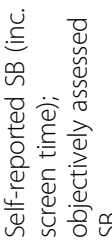

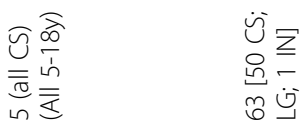

ํํำ

돈

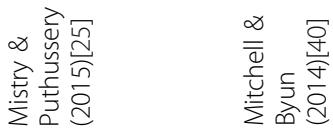




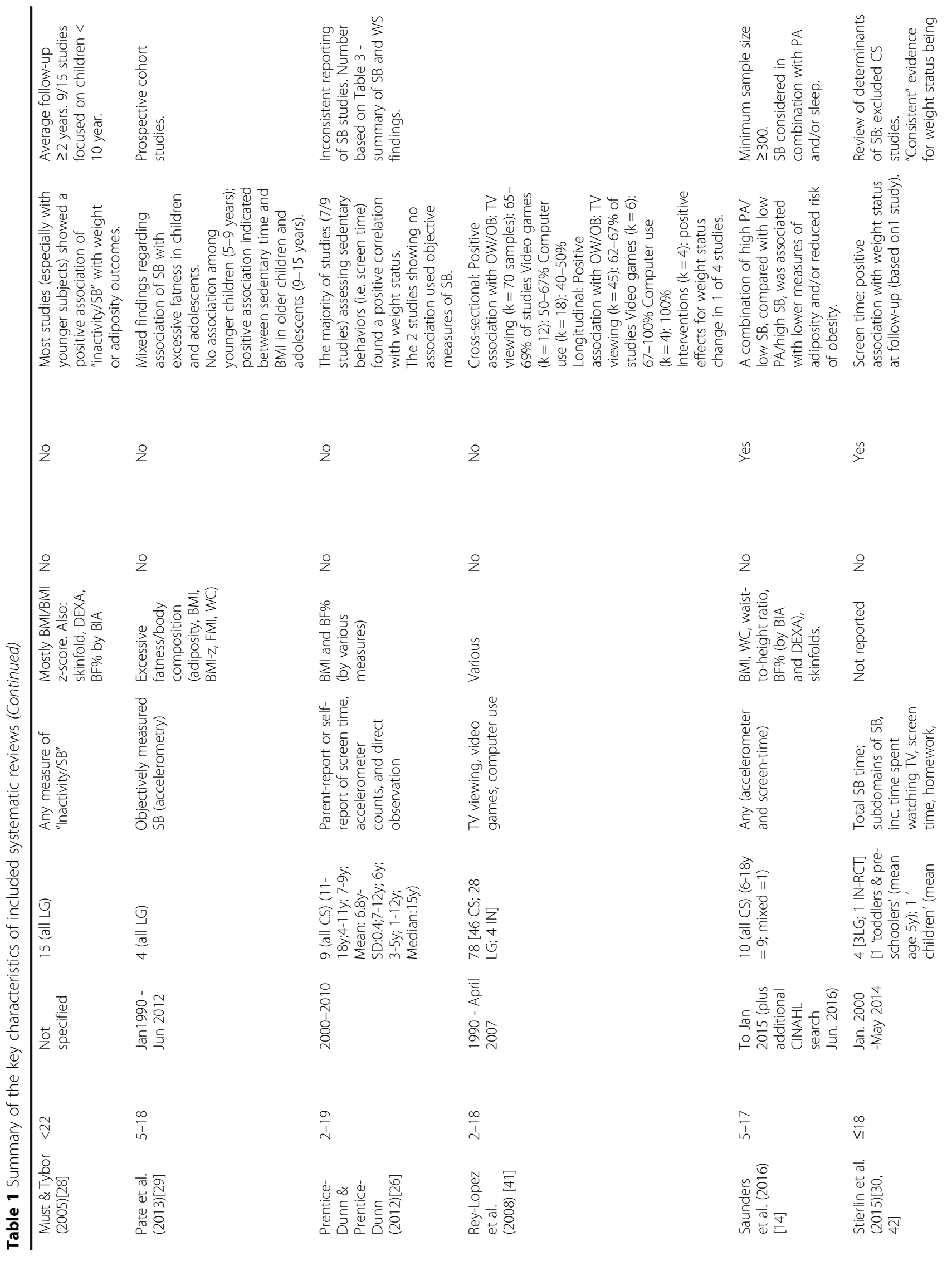




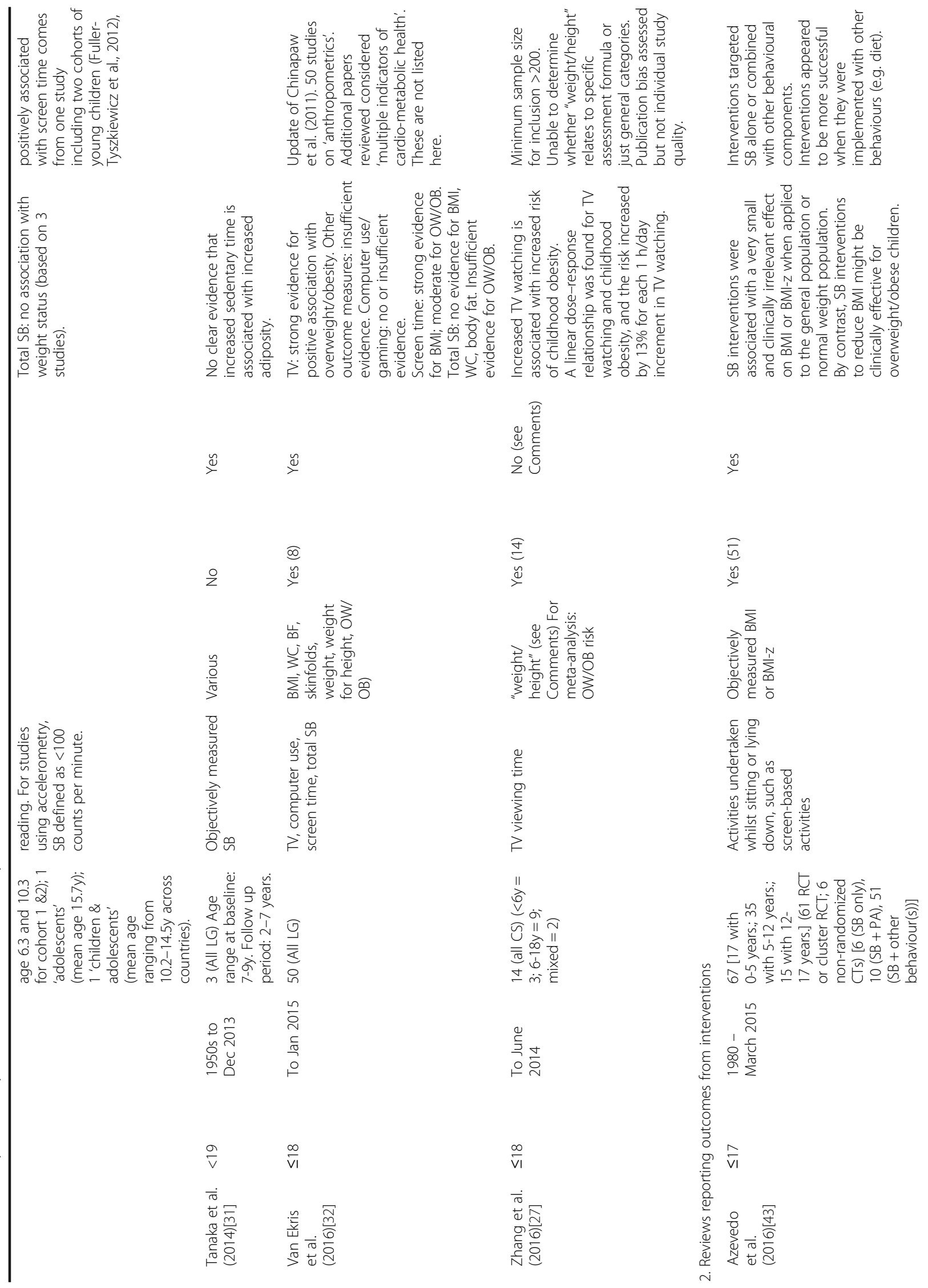




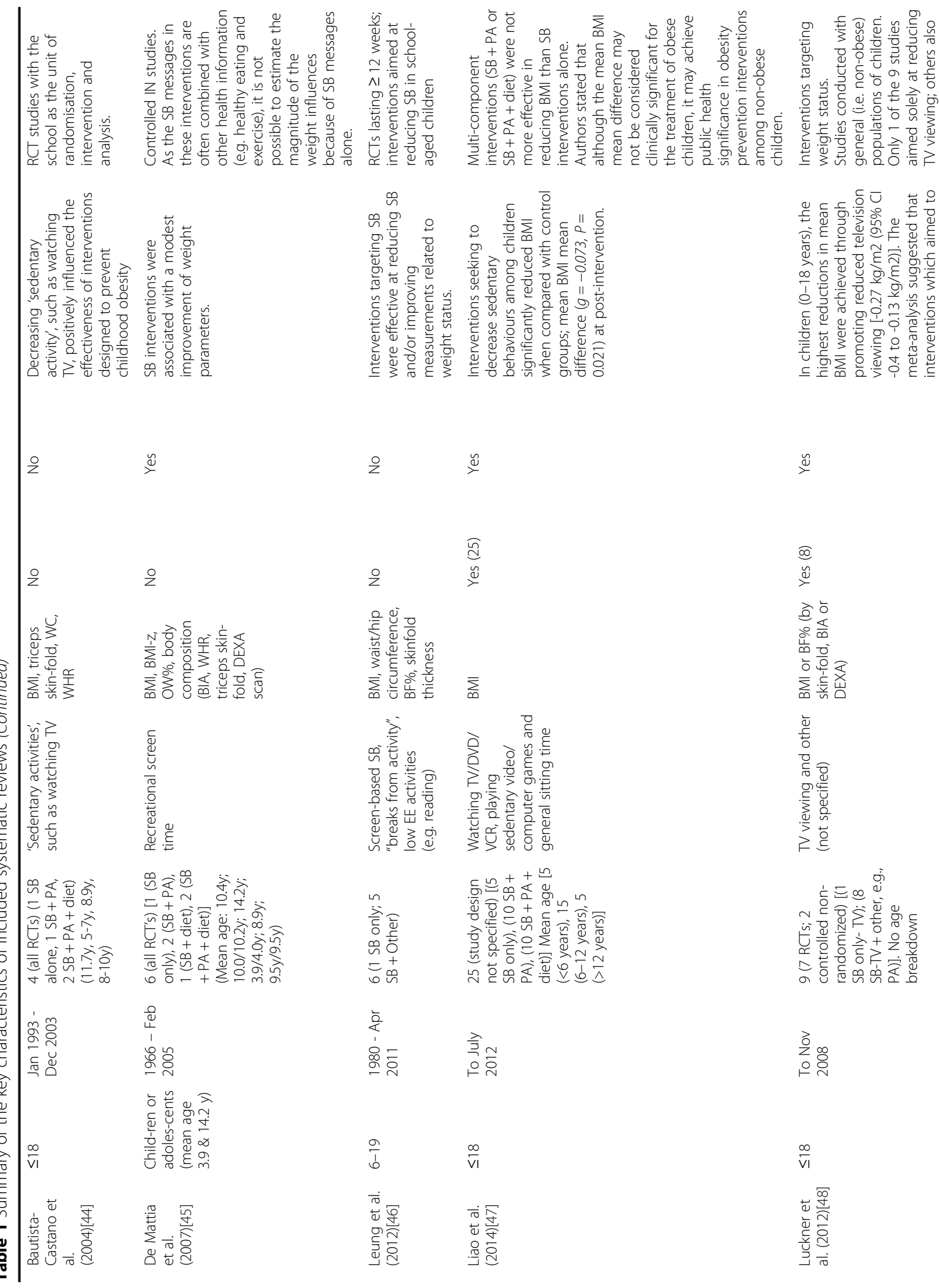




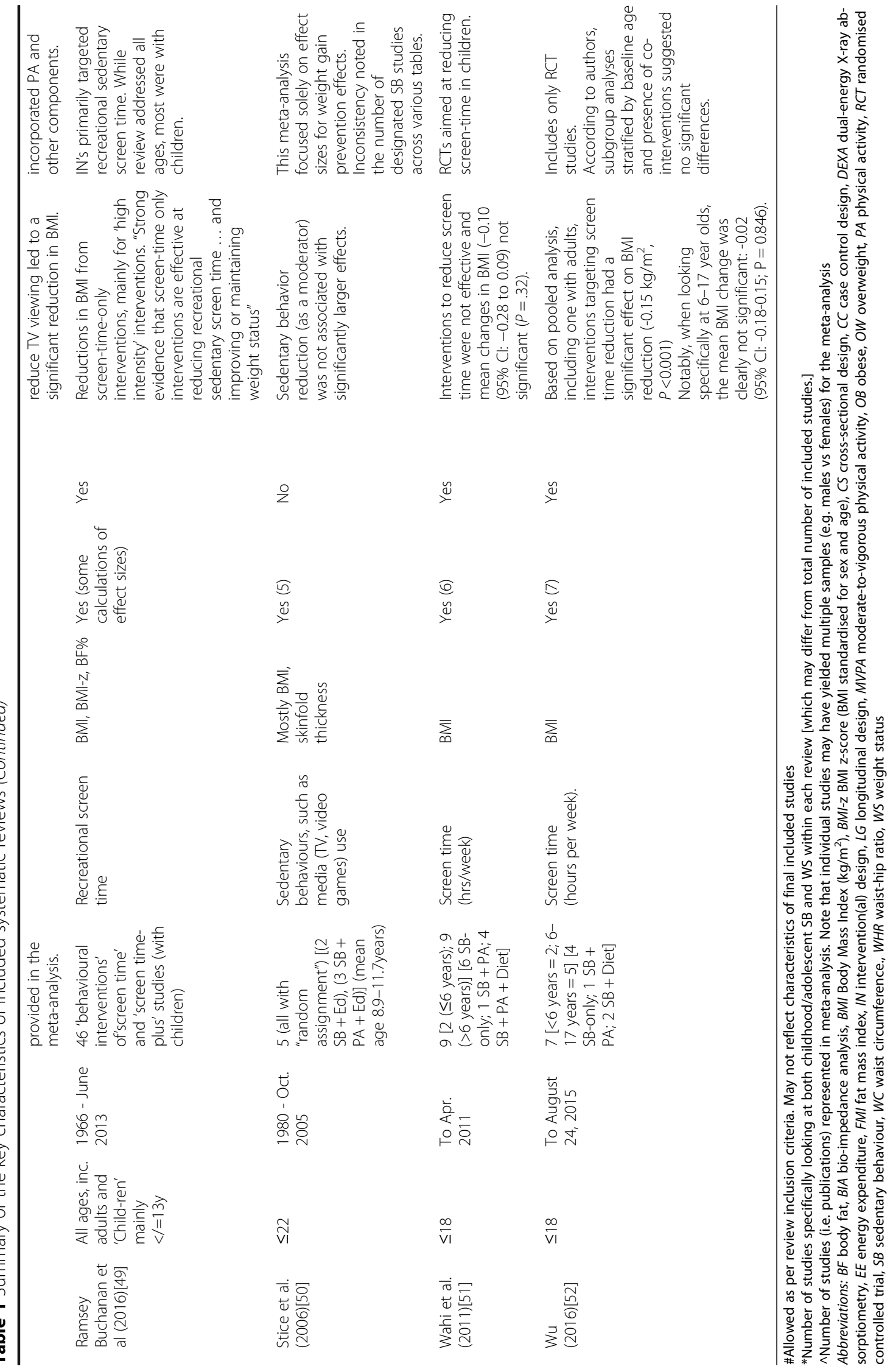


Table 2 Methodological quality assessment of systematic reviews using the AMSTAR rating

\begin{tabular}{|c|c|c|c|c|c|c|c|c|c|c|c|c|}
\hline \multirow[b]{2}{*}{ Author (Year) } & \multicolumn{12}{|c|}{ AMSTAR items } \\
\hline & 1 & 2 & 3 & 4 & 5 & 6 & 7 & 8 & 9 & 10 & $11^{*}$ & Overall rating \\
\hline Azevedo et al. (2016)[43] & Yes & Yes & No & No & No & Yes & Yes & Yes & Yes & Yes & Yes & 8 \\
\hline Bautista-Castano et al. (2004)[44] & No & No & No & No & Yes & Yes & No & No & N/A & No & No & 2 \\
\hline Carson et al. (2016)[33] & Yes & Yes & Yes & No & No & Yes & No & No & Yes & No & Yes & 6 \\
\hline Cliff et al. (2016)[34] & Yes & Yes & Yes & No & No & Yes & Yes & Yes & Yes & Yes & Yes & 9 \\
\hline Costigan et al. (2013)[35] & No & No & Yes & No & No & Yes & Yes & Yes & N/A & No & Yes & 5 \\
\hline DeMattia et al. (2007)[45] & Yes & No & Yes & No & Yes & Yes & No & No & Yes & No & Yes & 6 \\
\hline Fletcher et al. (2015)[36] & Yes & No & Yes & No & No & Yes & Yes & Yes & N/A & No & Yes & 6 \\
\hline Froberg \& Raustorp (2014)[37] & Yes & Yes & Yes & No & No & Yes & No & No & N/A & No & Yes & 5 \\
\hline Gorely et al. (2004)[38] & No & No & Yes & No & No & Yes & No & No & N/A & No & No & 2 \\
\hline Leech et al. (2014)[39] & No & No & Yes & No & No & Yes & No & No & N/A & No & Yes & 3 \\
\hline Leung et al. (2012)[46] & No & No & Yes & No & No & Yes & No & No & N/A & No & Yes & 3 \\
\hline Liao et al. (2014)[47] & No & No & Yes & No & No & Yes & Yes & Yes & Yes & Yes & Yes & 7 \\
\hline Luckner et al. (2012)[48] & No & No & No & No & No & Yes & Yes & No & Yes & Yes & Yes & 5 \\
\hline Marshall et al. (2004)[9] & No & No & Yes & No & No & No & No & No & Yes & No & Yes & 3 \\
\hline Mistry \& Puthussery (2015)[25] & Yes & No & Yes & No & No & Yes & Yes & Yes & Yes & No & Yes & 7 \\
\hline Mitchell \& Byun (2014)[40] & No & No & No & No & No & Yes & No & No & N/A & No & Yes & 2 \\
\hline Must \& Tybor (2005)[28] & No & No & $C / A$ & No & No & Yes & No & No & N/A & No & No & 0 \\
\hline Pate et al. (2013)[29] & No & Yes & No & No & No & Yes & No & No & N/A & No & Yes & 3 \\
\hline Prentice-Dunn \& Prentice-Dunn (2012)[26] & Yes & No & No & No & No & Yes & No & No & N/A & No & No & 2 \\
\hline Ramsey Buchanan et al. (2016)[49] & C/A & Yes & Yes & Yes & No & Yes & Yes & Yes & Yes & No & Yes & 8 \\
\hline Rey-Lopez et al. (2008)[41] & No & No & No & No & No & Yes & No & No & N/A & No & Yes & 2 \\
\hline Saunders et al. (2016)[14] & No & Yes & Yes & No & No & Yes & Yes & Yes & C/A & No & Yes & 6 \\
\hline Stice et al.(2006)[50] & No & No & Yes & Yes & No & Yes & No & No & Yes & No & Yes & 5 \\
\hline Stierlin et al. (2015)[30] & Yes & No & Yes & No & No & Yes & Yes & Yes & N/A & No & Yes & 6 \\
\hline Tanaka et al. (2014)[31] & No & No & $C / A$ & No & Yes & Yes & Yes & Yes & N/A & No & Yes & 5 \\
\hline Van Ekris et al. (2016)[32] & No & Yes & No & No & No & Yes & Yes & Yes & Yes & No & Yes & 5 \\
\hline Wahi et al. (2011)[51] & No & Yes & Yes & Yes & No & Yes & Yes & Yes & Yes & No & Yes & 8 \\
\hline Wu et al. (2016)[52] & No & Yes & Yes & No & No & Yes & Yes & No & Yes & Yes & No & 6 \\
\hline Zhang et al. (2016)[27] & No & No & Yes & No & No & Yes & No & No & Yes & Yes & Yes & 5 \\
\hline
\end{tabular}

${ }^{*}$ Criterion modified to only assess conflict of interest/source of funding statement of the review

AMSTAR contains 11-items to appraise the methodological aspects of the systematic reviews. All 11-items were scored as "Yes", "No", "Can't Answer" or "Not Applicable". AMSTAR comprises the following items:

1. 'a priori' design provided;

2. duplicate study selection/data extraction;

3. comprehensive literature search;

4. status of publication as inclusion criteria (i.e., grey or unpublished literature);

5. list of studies included/excluded provided;

6. characteristics of included studies documented;

7. scientific quality assessed and documented;

8. appropriate formulation of conclusions (based on methodological rigor and scientific quality of the studies);

9. appropriate methods of combining studies (homogeneity test, effect model used and sensitivity analysis);

10. assessment of publication bias (graphic and/or statistical test); and

11. conflict of interest statement

concluded 'no evidence' of an association from prospective studies when using objective assessments of sedentary behaviour for measures of BMI, waist circumference, and body fat, with the majority of studies being rated as high quality.

Patterns of associations across different outcome measures were largely unclear when assessed across all study designs, although van Ekris et al's [32] review of prospective studies showed 'moderate' or 'strong' evidence for an association for three out of four sedentary behaviour measures when the outcome was labelled as 'overweight/obesity'. For BMI, the most commonly used outcome measure, results ranged from 'no evidence' 
(computer use/game time; objective sedentary time), 'insufficient evidence' (TV viewing; overall sedentary time), to 'strong' (screen time). Given that few studies adopted standard methods to assess actual body fatness or waist circumference and, instead, adopted self-reported or objectively assessed BMI, the role of the outcome measure is still unclear.

In summary, evidence from systematic reviews synthesising observational cross-sectional studies indicates an association between TV viewing, screen time and adiposity in youth, and some evidence, but less clear, for the use of computers. Results from longitudinal designs are less convincing and appear to be somewhat dependent on the nature of the exposure and outcome variables assessed. Regardless of design, there is no evidence for an association with adiposity for total sedentary time assessed using accelerometers.

The strength of associations will be analysed and discussed later in our analysis of causality. In addition, results concerning potential moderators and confounders will be considered after data are presented from reviews of intervention studies.

\section{Evidence for an association between sedentary behaviour and adiposity from intervention studies}

Of the 10 systematic reviews reporting on adiposity effects from reductions in sedentary behaviour (all involving some form of screen time), 6 reported favourable changes in weight status [44-49] and 4 showed null or inconsistent effects [43, 50-52]. However, it is often difficult to assess the effects of interventions on adiposity outcomes from reductions in sedentary behaviour alone. Many interventions included additional behavioural components, such as physical activity and diet. For example, Ramsey-Buchanan et al's [49] recent review of screen time and 'screen time plus' interventions showed that the majority included more than just screen time reductions. When considering 8 screen time-only intervention study arms, the BMI change ranged from -0.09 to -0.44 , whereas from 37 screen time-plus intervention study arms it ranged from -0.08 to -0.21 . While interventions considered more intense were seen to be more successful at behaviour change, the changes in adiposity and weight status could be considered quite modest. This is similar to results from an earlier review by DeMattia et al. [45] who concluded that interventions were "associated with improvement of weight parameters" but also stated that "the magnitude ... is modest and is difficult to interpret, because normal BMI ranges vary with age and development in children" (p. 79). Wahi et al's [51] review showed no effectiveness for interventions in reducing markers of adiposity, while the review by $\mathrm{Wu}$ et al. [52], when excluding one trial on adults, showed no change in BMI from six interventions.
A recent meta-analysis by Azevedo et al. [43] concluded that interventions are associated with changes in $\mathrm{BMI} / \mathrm{BMI}-\mathrm{Z}$ score, but these were reported as "very small" ( $\mathrm{SMD}=-0.060,95 \% \mathrm{CI}:-0.098$ to -0.022 ). The reduction in BMI was greater in those who were overweight, and interventions were more effective when implemented in children, as a multicomponent intervention, and delivered in a non-educational setting. Overall, interventions to reduce sedentary behaviour in young people have been shown to produce modest effects for weight status and adiposity.

\section{Analysis of evidence concerning causality}

The degree to which sedentary behaviour and adiposity in young people can be assessed as being causally associated is mainly through the following 'Bradford Hill criteria' [19]: strength of association, consistency, specificity, temporality, coherence and biological plausibility, dose-response, and experimental evidence. Table 3 defines each of these factors and summarises key findings.

Support for strength of association is weak. Starting from the first meta-analysis investigating TV viewing and body fatness in youth by Marshall et al. [9] ( $r=$ 0.066), to a recent review concerning objective measures of sedentary behaviour by Cliff et al. [34] $(r=0.07)$, effect sizes are very small, though both are significant. When comparing highest versus lowest TV categories, Zhang et al. [27] calculated an odds ratio of 1.47 for obesity, considered just below the lower threshold for 'moderate' strength [24]. However, this value is similar to that for sedentary behaviour and all-cause mortality in adults [5]. In a statistical integration of nine prospective samples, van Ekris et al. [32] reported an effect close to zero for the relationship between baseline TV viewing and BMI at follow-up when controlling for baseline BMI. Inspection of their Forest plot shows large variation, with 3 of the samples showing significant effects, but overall a range of beta values from -0.02 to 0.317 . Some reviews only report the direction rather than strength of association [35].

The strength of effect from interventions is small-tomoderate, with some effects significant and others not. The largest effects are for high intensity screen time interventions on BMI (median reduction $=-0.44$ ) [49]. The most recent meta-analysis of 51 interventions [43] has reported an effect size (SMD) of only -0.06, although this was significant. This is similar to Liao et al's [47] result (Hedges' $g=-0.073$ ) which was also significant. Overall, therefore, strength of association is small, although sometimes significant. This raises the issue of whether such values reflect clinically meaningful or practical values. 
Table 3 Assessment of causality using assessments of strength of association, consistency, specificity, temporality, coherence and biological plausibility, dose-response, and experimental evidence

\begin{tabular}{|c|c|c|c|}
\hline & Definition & Summary o & ff evidence \\
\hline & & Support? & \\
\hline $\begin{array}{l}\text { Strength of } \\
\text { association }\end{array}$ & $\begin{array}{l}\text { How strong is the association between sedentary } \\
\text { behaviour and adiposity in young people? }\end{array}$ & Weak & $\begin{array}{l}\text { Consistently low strength of association values from cross- } \\
\text { sectional evidence for self-reported screen time and objectively } \\
\text { assessed sedentary time (e.g., } r<0.01) \text {; values close to zero for } \\
\text { BMl per additional hour/day of screen time in prospective } \\
\text { studies; small significant and non-significant effects from } \\
\text { interventions. }\end{array}$ \\
\hline Consistency & $\begin{array}{l}\text { How consistent is the evidence across different } \\
\text { populations and in different settings? }\end{array}$ & $\begin{array}{l}\text { Moderate- } \\
\text { to-weak }\end{array}$ & $\begin{array}{l}\text { Evidence on sex differences in inconclusive. Stronger evidence } \\
\text { exists for an association in children than adolescents but this } \\
\text { could be a function of the volume of research favouring } \\
\text { younger age groups, as well as the issue of maturation } \\
\text { confounding measures of adiposity. Evidence does not differ } \\
\text { by country. } \\
\text { Consistency across measures of sedentary behaviour and } \\
\text { markers of adiposity is weak. }\end{array}$ \\
\hline Specificity & $\begin{array}{l}\text { Is adiposity mainly limited to the existence } \\
\text { of sedentary behaviour? }\end{array}$ & No & $\begin{array}{l}\text { It is clear that many factors can be listed that are associated with } \\
\text { weight gain or higher levels of adiposity in young people. The } \\
\text { factor of specificity, therefore, cannot be supported. However, } \\
\text { Hill states that we must not overemphasise this issue because } \\
\text { diseases may have more than one cause and that "one-to-one } \\
\text { relationships are not frequent" (p. 297). }\end{array}$ \\
\hline Temporality & $\begin{array}{l}\text { Does sedentary behaviour precede the development } \\
\text { of adiposity? }\end{array}$ & Weak & $\begin{array}{l}\text { Reviews addressing prospective studies show a mixed pattern of } \\
\text { results. Data on self-reported screen time have shown 'strong' } \\
\text { evidence for an association with BMl, but 'insufficient' for other } \\
\text { measures of adiposity. Evidence concerning objective measures } \\
\text { of total sedentary behaviour is largely null. }\end{array}$ \\
\hline $\begin{array}{l}\text { Coherence and } \\
\text { biological } \\
\text { plausibility }\end{array}$ & $\begin{array}{l}\text { Any interpretation of the data should not seriously } \\
\text { conflict with what is known about weight status } \\
\text { and adiposity in young people. Biological } \\
\text { plausibility provides further support for causation. }\end{array}$ & Moderate & $\begin{array}{l}\text { While it is plausible and coherent with current knowledge that } \\
\text { low energy expenditure in the form of sitting could be } \\
\text { obesogenic, often these behaviours (e.g., TV viewing) co-exist } \\
\text { with other behaviours. These might include excessive dietary } \\
\text { intake and prompts from TV advertising for unhealthy foods. } \\
\text { Individual sedentary behaviours are usually correlated in only a } \\
\text { small way with moderate-to-vigorous physical activity, thus it } \\
\text { cannot be claimed that one sedentary behaviour automatically } \\
\text { precludes being physically active over time. }\end{array}$ \\
\hline Dose-response & $\begin{array}{l}\text { Do higher levels of sedentary behaviour show } \\
\text { higher levels of adiposity? }\end{array}$ & Yes & $\begin{array}{l}\text { Two reviewers provide support for a dose-response relationship. } \\
\text { Carson et al. showed that more or less regardless of how TV } \\
\text { viewing categories were compared, higher viewing was } \\
\text { associated with greater adiposity. Zhang et al. calculated an } \\
\text { odds ratio per } 1 \text { h/day increment in TV watching as } 1.13 \\
\text { (95\% Cl 1.03-1.19). Graphical data suggested a linear relationship. }\end{array}$ \\
\hline $\begin{array}{l}\text { Experimental } \\
\text { evidence }\end{array}$ & $\begin{array}{l}\text { Is there evidence from interventions using } \\
\text { experimental methods for changes in adiposity } \\
\text { to result from changes in sedentary behaviour? }\end{array}$ & Weak & $\begin{array}{l}\text { The analysis we have undertaken in this review of reviews } \\
\text { summarises the evidence concerning effectiveness from } \\
\text { interventions as 'modest', although some groups (e.g., obese) } \\
\text { may gain more benefit. Effect sizes from meta-analyses, however } \\
\text { expressed, are mostly small and both significant and } \\
\text { non-significant. }\end{array}$ \\
\hline
\end{tabular}

Evidence for consistency of findings is moderate-toweak. Consistency across demographics, such as age and sex, is reasonable, while it is less consistent for different sedentary behaviours and markers of adiposity. While the evidence is somewhat supportive of stronger associations for younger children, it is not clear if this is due to the confounding of maturational status in older cohorts.

Evidence for specificity is clearly not supported. One cannot find, nor would one expect, data supporting the view that obesity is primarily due to sedentary behaviours rather than a lack of MVPA or unhealthy dietary intake. Hill [19] states that this does not necessary preclude a conclusion supporting causation as it is rare to find a disease or condition (i.e. obesity) to have a single behavioural cause.

Support for the temporal sequence from sedentary behaviour leading to adiposity outcomes is weak. Using prospective data for both self-reported screen time and objectively assessed total sedentary time, the evidence appears to be mixed. For example, screen time has been shown to have 'strong' associations with BMI, but 'insufficient' evidence exists for other adiposity measures. 
Moreover, objective measures preceding assessments of adiposity show largely null findings. It is plausible, though rarely tested in young people, for higher levels of adiposity to lead to greater sedentary behaviour - socalled 'reverse causality'. Indeed, it is plausible also for 'reciprocal causality' with a cycle of higher obesity, higher sedentary behaviour, and further increases in adiposity, thus making it difficult to know what might come first. In addition, with a few exceptions, follow-up periods in prospective studies are often quite short compared to those for adults and all-cause mortality [5]. From the 50 prospective studies reviewed by van Ekris et al. [32], follow-up averaged 3.15 years (range: 8 weeks to 8 years), with $84 \%$ less than 5 years, and nearly half less than 2 years.

There is moderate support for coherence and biological plausibility in the research on young people. Logically, low energy expenditure from periods of sitting should be associated with measures of adiposity, overweight and obesity. However, many studies do not adequately control for important potential confounders, such as physical activity, diet or maturational status. With evidence showing only small associations between MVPA and sedentary behaviour [17], it is proposed that both can co-exist across the day. This means that we need to control for MVPA or analyse data for those differing in levels of MVPA. It is the former strategy that has mainly been adopted, if indeed physical activity is controlled for at all. However, given that the associations between sedentary behaviour and adiposity are small, attenuation effects for MVPA may be limited. In Mitchell and Byun's review [40], all 6 cross-sectional studies where a moderation analysis was conducted showed that associations between screen time and BMI were only evident when MVPA was low. In addition, research suggests that the difference in energy expenditure between sitting and standing still is very small [53].

Froberg and Raustorp's [37] review of objectively assessed sedentary behaviour showed that adiposity was largely unrelated to sedentary behaviour even when controlling for levels of MVPA. Costigan et al's [35] review of adolescent girls showed in a summary table that nine of 10 cross-sectional studies reported a positive association between screen time and weight status, but only five controlled for physical activity (and three studies appeared to be missing from the analysis). For longitudinal studies, they concluded all six had positive associations, with only half controlling for physical activity. From their table of results, only one longitudinal and two cross-sectional studies reported positive associations between screen time and weight status, controlled for physical activity, and had a low risk of bias rating. But the overall conclusion from this review was that a 'strong' association existed.
Unhealthy dietary intake has been shown to be associated with higher levels of screen time (including TV viewing) for adults, adolescents and children [18]. Some have argued that this may be the mechanism accounting for any association between screen time and adiposity. Few studies have controlled for dietary intake in their assessment of the association between sedentary behaviour and weight status. Contrary to expectations stemming from the reviews on screen time and dietary intake, Fletcher et al. [36] showed that any associations between screen time and adiposity were largely independent of diet. However, the variability in assessments of different dietary items was large. Moreover, the strength of association between key variables was not reported.

Studies in which statistical clustering of diet, physical activity and sedentary behaviour were reviewed by Leech et al. [39] but they found none that looked only at the clustering of sedentary behaviour and diet. When all three behaviours were assessed, clusters were shown to be associated with adiposity in adolescents. The independent or synergistic roles of sedentary behaviour were not clear.

In conclusion, there is biological plausibility as well as some level of coherence in showing TV viewing to be associated with a less healthy diet and greater snacking. However, the evidence is only moderate due to a lack of data testing whether true moderation effects exist for those who are physically active or inactive, and those who consume largely healthy or unhealthy diets. It is equally plausible that levels of adiposity will only be associated with sedentary behaviour for those who are inactive and have unhealthy diets. Sleep patterns may also need to be accounted for [15].

Dose-response, or biological gradient, is an important factor for determining causality. While dose-response curves can take on different shapes, and some associations may be more of a stepped or threshold function than a linear one, some gradient might be expected. From two analyses of dose-response, there is support for a gradient. For example, Zhang et al's [27] review is the only meta-analysis to directly test for a dose-response effect, and they show that adiposity increases for each additional hour of TV viewing by odds of 1.13. Their graphical interpretation of the data suggests a linear effect. This is somewhat contradicted by the data from van Ekris et al [32] who report close to zero effects on adiposity for each additional daily hour of screen time. Carson et al. [33] showed that higher categories of TV viewing were associated with higher levels of adiposity. Given the analysis by Zhang et al., we conclude that there is evidence for a dose-response association between sedentary behaviour and adiposity in youth, however the magnitude of this trend appears to be small. 
Finally, we conclude that there is only weak evidence from experimental designs for an effect of sedentary behaviour on changes in adiposity. Most effects are modest at best, with some being null. Some populations, such as those already obese, may have more to gain and show greater experimental effectiveness.

In summarising our assessment of the evidence concerning the association between sedentary behaviour and weight status or adiposity in young people, we conclude that there is no evidence to support causality. As shown in Table 3, evidence for strength of association is weak, consistency is moderate-to-weak, specificity is not supported, temporality is weak, coherence and biological plausibility is moderate, experimental evidence is weak, but there is evidence for a small dose-response association.

\section{Discussion}

The purpose of this synthesis was to critically analyse the voluminous literature concerning the association between sedentary behaviour, usually in the form of either screen time or objectively assessed total sedentary time, and markers of weight status or adiposity in children and adolescents. Our research synthesis was conducted to answer four research questions. First, is there an association between sedentary behaviour and adiposity in young people? Our conclusion is that this association has been demonstrated but is small and somewhat inconsistent. Second, does this association differ by type of sedentary behaviour and type of marker of adiposity? Our conclusion is that screen time behaviours show some associations, but not objectively assessed total sedentary time. BMI has been studied most often but it is difficult to make clear comparisons between outcome measures.

Third, do MVPA or dietary intake moderate this association? Our conclusion is that too few studies control for dietary intake. One review of 21 observational studies concludes that sedentary behaviour is associated with adiposity in youth independently of dietary intake while another review has shown that screen time is associated with consumption of a less healthy diet. Studies controlling for MVPA have shown mixed findings, with some evidence of attenuation, but very few studies have tested for moderation effects. Those that have supported effects for adiposity from sedentary behaviour are mainly for those young people low in MVPA [40].

Finally, to what extent can any association between sedentary behaviour and adiposity be considered causal? Our conclusion is that while there is some evidence for a small dose-response relationship, other key factors, including strength of association and experimental evidence, is largely weak. Causality cannot be established given the current evidence base.
This popular and quite long established field of research is replete with uncertainty. Dietz and Gortmaker [7] claimed that TV was causally associated with body fatness in young people, yet this was based on only one, albeit large, observational study. Subsequently, the meta-analysis by Marshall et al. [9] showed a significant but very small effect size for mainly cross-sectional studies, claiming that it was likely to be of limited clinical relevance. But a recent very large international crosssectional study of over 207,000 adolescents and 77,000 children from 54 countries concluded that TV viewing was associated with BMI in a dose-response fashion [54]. The authors of this study also stated that their conclusion supported two of the reviews we have assessed in the present omnibus review $[9,41]$. However, the review by Marshall et al. [9], as just stated, showed a very small association, while the review by Rey-Lopez et al. [41] did not quantify the strength of association nor test for dose-response effects. In short, there appear to be numerous interpretations of the nature and importance of any association between sedentary behaviour and adiposity in young people.

\section{Are associations 'sufficient' and meaningful?}

It is clear that many studies do report positive associations between sedentary behaviour and markers of adiposity in young people when the behaviour is selfreported as some form of screen time. But, as we discussed in the assessment of strength of association, the magnitude of this relationship is small. This was not disputed by Dietz and Gortmaker [7]. Marshall et al. [9] questioned whether such an association was clinically relevant, while Hancox and Poulton [55], in an analysis of longitudinal data on TV viewing and BMI, concluded that while the effect is small, there is a case to be made in support of the importance of TV viewing for childhood obesity.

There seems to be no dispute that the strength of association for screen time is small. The key issue is how meaningful is this association? Given that nearly all children and adolescents watch TV and use computers, a small 'effect' across a very large population could be significant for public health. On the other hand, analyses are mainly with those in healthy ranges of BMI. Moreover, children and adolescents are usually considered the most active and 'healthy' segment of society and, notwithstanding current obesity data, are largely free of non-communicable diseases common in adults. This raises the issue of whether we should expect much of an association.

In Liao et al.'s meta-analysis [47] of sedentary behaviour interventions, they concluded "Although the observed magnitude of BMI mean differences $(g=-0.073$, $P=0.021)$ between intervention and control groups at 
post-intervention may not achieve a level considered to be clinically significant (a minimum of 0.25 standardized BMI unit reduction) for the treatment of obese children, it may be approaching the magnitude of change required to achieve population-level public health significance in obesity prevention interventions among non-obese children, which is not entirely known" (p. 164; emphasis added).

Hancox and Poulton [55] raise an important point in suggesting that the small associations for screen time and adiposity in youth may not be too different from other associations that we seem to accept as meaningful. They cite three studies supporting their view that physical activity is related to BMI in only a small way, or not at all. That said, Ness et al. [56], while reporting data from both objective physical activity and fat mass (using a dual x-ray emission absorptiometry - DEXA), concluded that there was a "strong negative dose-response association" (p. 481) with the most adjusted model accounting for TV viewing as a confounding variable.

As stated in our results, Zhang et al. [27] reported an odds ratio of 1.47 for obesity from cross-sectional TV viewing studies, when comparing highest versus lowest TV categories. While this is just below the lower threshold for 'moderate' strength [24], it does suggest an association between more extreme groups. On the other hand, van Ekris et al. [32] reported an effect close to zero for TV viewing and BMI prospective studies and only 3 of 9 samples showed significant effects.

Even with small effects, screen time may still be important for adiposity over time. As we have reported, Hancox et al. [8] showed prospective associations of TV viewing on adiposity over the transition into young adulthood, and Thorp et al. [57], in reviewing adult studies, concluded that there was a consistent relationship between sedentary behaviour and weight gain from childhood into adulthood. These findings suggest that we need to know more about the tracking of sedentary behaviour into adulthood [58] and the possible cumulative effect of such behaviours on adiposity.

In summary, the issue of strength of association and the 'meaningfulness' of any association remains a contentious issue. There is agreement that associations and effects are essentially small, yet the interpretation of these, and their public health importance, is still open to debate.

\section{Can we rule out alternative explanations?}

Given the extensive number of cross-sectional studies, some of which have been large and influential [7, 54], and the mixed conclusions from prospective studies [32], it is plausible that young people with greater adiposity choose to engage in higher levels of sedentary behaviour. This 'reverse causality' hypothesis has rarely been properly tested, but remains plausible, as does a 'reciprocal causality' cycle. That said, there are studies showing some direction of effect from longitudinal studies [8], increasing confidence that it could be screen time preceding adiposity. But overall, our conclusion concerning the temporal sequencing of effects remains weak.

Another plausible explanation is that the association between sedentary behaviour and adiposity is a spurious one, caused by other co-existing variables. The main candidates are physical activity and dietary intake, and possibly sleep. For moderate-to-vigorous physical activity, the evidence is mixed, with some studies showing associations between sedentary behaviour and adiposity even when controlling for MVPA, but others suggesting the effects are only evident for those with low MVPA. The latter would suggest that MVPA can over-ride the negative effects of sedentary behaviour, but with many people not meeting recommended levels of MVPA, sedentary behaviour may still be important.

The evidence concerning diet is also somewhat mixed. It has been shown that screen time is associated with less healthful eating [18], yet one review concludes that associations between sedentary behaviour and adiposity are not affected by diet [36]. Limitations of the studies in this field include the measures of diet, and timing of assessments. Dietary intake is notoriously difficult to assess through self-report and measurement error will be high. Moreover, studies have not assessed diet contemporaneously with specific sedentary behaviours. All we can conclude from studies is that some sedentary behaviours (e.g. TV viewing) are statistically associated with markers of dietary intake. We are not able to conclude that the sedentary behaviour occurred at the same time as unhealthy eating or that the two are causally linked. It is equally plausible that unhealthy snacking, for example, is part of a wider set of clustered unhealthy behaviours, such as high sedentary behaviour, low MVPA, poor sleep hygiene, and smoking.

In conclusion regarding alternative explanations, there is some evidence that sedentary behaviour is not harmful to health for those who are sufficiently physically active, showing that any associations with adiposity cannot be seen as totally independent of MVPA, and that dietary patterns may also co-exist with sedentary behaviour. In both cases the evidence is somewhat inconclusive, suggesting that we cannot yet rule out alternative explanations.

\section{What might be explaining associations between sedentary behaviour and adiposity?}

Although the association between sedentary behaviour and adiposity is, in our analysis, quite weak, there is evidence that some association does exist for screen time. 
Given that conclusion, we need to identify potential mechanisms for such effects. The most obvious is that sedentary behaviours are, by definition, low energy expenditure behaviours [1]. But the key issue is energy expenditure across the day and the levels of energy intake. This is why levels of physical activity must be accounted for alongside diet.

There has often been an assumption that sedentary behaviour displaces more physically active pursuits, and this explains some of the links to obesity. However, while engaging in a sedentary behaviour inevitably precludes physical activity at that specific time, we know that levels of MVPA are only related to sedentary behaviours in a small way. This refutes the so-called 'displacement hypothesis'. Such a hypothesis would be supported only if we can demonstrate that people engaging in high levels of sedentary behaviours are also less physically active. This has not generally been shown. Over a 24-h period we can take part in a variety of behaviours, ranging from sleep, sedentary, light activity, and MVPA, to highly vigorous physical activity. Being sedentary will most likely displace some light activity (e.g. sitting and standing are mutually exclusive and somewhat co-dependent), but reducing the time sitting in a day may have little effect on how much MVPA is undertaken. Future research must take into account the co-dependence of constructs across a movement continuum which includes sleep, sedentary behaviour, light physical activity, and MVPA. At any one time, an individual can only do one of these behaviours. Changes in one (e.g. TV viewing) must be displaced to another [59].

With the evidence that screen time (including TV viewing) is more likely to show an association with adiposity than overall sedentary time, this suggests that messages emanating from screens, such as advertisements for unhealthy foods, might be a factor. This could be coupled with more 'mindless' eating in front of the TV and therefore possible over-consumption. Strasburger et al. [60] concluded that the media have a significant impact on adolescent's eating behaviours, and that parents should be encouraged to turn off the TV during mealtimes. But equally, they say that the role of media is complex and is in need of further research.

Measurement issues are important in understanding our findings, including both the measurement of exposure and outcome variables. With our clear conclusion that objectively assessed sedentary time is largely unrelated to markers of adiposity in youth, we can conclude that either sedentary behaviour throughout the day is not important for adiposity, or that only certain types and contexts of sedentary behaviour are influential. The latter infers that it is not just sitting that is a risk factor for greater adiposity, but the type of sitting and its coupling with other behaviours. But it might also suggest a measurement issue. For example, if screen viewing shows slightly higher and more consistent associations with weight status, this could be because it is easier to recall the amount (and possibly context) of this behaviour. Most people know the length of TV programs, for example, but may struggle to recall time spent reading or driving in a car.

BMI is the most common measure of weight status used in the various reviews. Whilst simple and useful at a population level for the estimation of overweight/obesity levels in adults, its use in children is confounded by the growth and maturation issues associated with significant anthropometric changes in a relatively short period. To address this, relative BMI $\mathrm{z}$-scores (standard deviation scores) have been developed to account for a child's age and sex. Several of the reviews we analysed included BMI-z as a measure of obesity, however few reviews specifically analysed this. Moreover, the issue of pubertal maturation is particularly troublesome when considering longitudinal studies in children and adolescents. Significant changes in relative proportions of lean and fat mass may confound results if not adjusted for in a meaningful way. This may be one reason why longitudinal evidence in younger, pre-pubertal children may be a little stronger. Must and Tybor [28], for instance, concluded that most studies - especially with younger participants - showed a positive association of "inactivity/ sedentary behaviour" with weight or adiposity outcomes. By contrast, Pate et al [29] concluded that there was no association among younger children (5-9 years) but a positive association between sedentary time and BMI in older children and adolescents (9-15 years). Stierlin et al [30] concluded that "consistent" evidence existed for weight status being positively associated with screen time but the evidence stemmed from one study including two cohorts of young children. In future, studies will need to account for maturational status to aid interpretation of weight status results in young people.

Finally, Hancox and Poulton [55] raise an interesting issue that while the association between TV viewing and adiposity might be small, this could be an underestimation due the lack of young people who watch no $\mathrm{TV}$ at all. In other words, all analyses involve young people who watch at least 'some' TV and either compare them with those who watch a great deal more, or calculate associations using TV viewing time that is represented by a truncated range of values (i.e. does not include values at or near zero).

\section{Conclusions}

Using the evolving methodology of a systematic 'review of reviews', we were able to provide the following answers to our main research questions: 
1. Is there an association between sedentary behaviour and adiposity in young people? If so, does this association differ by type of sedentary behaviour and type of marker of adiposity? Evidence from observational cross-sectional studies indicates a small association between TV viewing, screen time and adiposity in youth, and some evidence, but less clear, for the use of computers. Results from longitudinal designs are less convincing and appear to be somewhat dependent on the nature of the exposure and outcome variables assessed. There is no evidence for an association with adiposity for total sedentary time assessed using accelerometers. Interventions have been shown to produce modest effects for weight status and adiposity. Effects may be greater in more obese populations. Most studies assessed BMI, but no clear conclusions can be drawn concerning diverse results resulting from the assessment of different outcome measures.

2. Do MVPA or dietary intake moderate this association? TV viewing has been shown to be associated with a less healthy diet and greater snacking although evidence for true moderation is still unclear. Evidence is emerging suggesting that greater adiposity (and other negative health effects) may be most pronounced for those not engaging in high amounts of MVPA.

3. To what extent can any association between sedentary behaviour and adiposity be considered causal when using key criteria proposed by Hill [19]? There is no evidence to support a causal association between sedentary behaviour and weight status in young people. Evidence for strength of association is weak, consistency is moderate-to-weak, specificity is not supported, temporality is weak, coherence and biological plausibility is moderate, experimental evidence is weak, but there is evidence for a small dose-response association.

This remains a complex field with different exposure and outcome measures and research designs. But claims for 'clear' associations between sedentary behaviour and adiposity in youth, and certainly for causality, are either premature or misguided.

\section{Acknowledgements}

Not applicable.

Funding

Not applicable.

\section{Availability of data and materials}

Any additional data not presented in the paper and deemed to support the findings of this study are available from the first author.

\section{Authors' contributions}

SJHB provided the conceptualisation for the paper and wrote the first full draft of the manuscript. EGB and GW conducted searches and extracted data. All authors checked data extraction and performed analyses. All authors contributed to the writing and editing of the manuscript, and read and approved the final manuscript.

\section{Competing interests}

SJHB: Funding has been received since 2013 for consultancy work from Fitness First, Nuffield Health, Unilever. None of these are currently active. Funding was received in 2016 for consultancy work for Halpern PR Limited. In-kind support through the provision of a sit-to-stand desk was provided by Ergotron from 2012-2014. Advice has been requested by and offered to Active Working, Get Britain Standing, and Bluearth, none with funding.

EGB: no competing interests

GW: no competing interests

\section{Consent for publication}

Not applicable.

Ethics approval and consent to participate

Not applicable.

\section{Publisher's Note}

Springer Nature remains neutral with regard to jurisdictional claims in published maps and institutional affiliations.

\section{Author details}

${ }^{1}$ Institute of Sport, Exercise \& Active Living, Victoria University, Melbourne, Australia. ${ }^{2}$ Institute for Resilient Regions, University of Southern Queensland, Education City, 37 Sinnathamby Boulevard, Springfield Central, QLD 4300, Australia. ${ }^{3}$ McGill University, Montreal, Canada.

Received: 8 January 2017 Accepted: 20 March 2017

Published online: 28 March 2017

\section{References}

1. Network SBR. Letter to the Editor: Standardized use of the terms "sedentary" and "sedentary behaviours". Appl Physiol Nutr Metab. 2012;37:540-2.

2. Owen N, Healy GN, Matthews CE, Dunstan DW. Too much sitting: the population health science of sedentary behavior. Exerc Sport Sci Rev. 2010; 38(3):105-13.

3. Biswas A, Oh PI, Faulkner GE, Bajaj RR, Silver MA, Mitchell MS, Alter DA. Sedentary time and its association with risk for disease incidence, mortality, and hospitalization in adults: a systematic review and meta-analysis. Ann Intern Med. 2015;162:123-32.

4. Wilmot EG, Edwardson CL, Achana FA, Davies MJ, Gorely T, Gray LJ, Khunti $\mathrm{K}$, Yates T, Biddle SJH. Sedentary time in adults and the association with diabetes, cardiovascular disease and death: systematic review and metaanalysis. Diabetologia. 2012;55(11):2895-905.

5. Biddle SJH, Bennie J, Bauman A, Chau J, Dunstan D, Owen N, Stamatakis E, van Uffelen J. Too much sitting and all-cause mortality: is there a causal link? BMC Public Health. 2016;16(1):635.

6. Ekelund U, Steene-Johannessen J, Brown WJ, Fagerland MW, Owen N Powell KE, Bauman A, Lee IM, for the Lancet Physical Activity Series 2 Executive Committee and the Lancet Sedentary Behaviour Working Group: Does physical activity attenuate, or even eliminate, the detrimental association of sitting time with mortality? A harmonised meta-analysis of data from more than 1 million men and women. Lancet. 2016:388:1302-10.

7. Dietz WH, Gortmaker SL. Do we fatten our children at the television set? obesity and television viewing in children and adolescents. Pediatrics. 1985; 75:807-12.

8. Hancox RJ, Milne BJ, Poulton R. Association between child and adolescent television viewing and adult health: a longitudinal birth cohort study. Lancet. 2004;364:257-62.

9. Marshall SJ, Biddle SJH, Gorely T, Cameron N, Murdey I. Relationships between media use, body fatness and physical activity in children and youth: a meta-analysis. Int J Obes. 2004;28:1238-46.

10. Saelens BE. Helping individuals reduce sedentary behavior. In: Andersen RE, editor. Obesity: etiology, assessment, treatment, and prevention. Champaign, IL: Human Kinetics; 2003. p. 217-38. 
11. The Australian College of Paediatrics. Position statement: Children's television. J Paediatr Child Health. 1994;30:6-8.

12. Bar-Or O, Foreyt J, Bouchard C, Brownell KD, Dietz WH, Ravussin E, Salbe AD, Schwenger S, St Jeor S, Torun B. Physical activity, genetic, and nutritiona considerations in childhood weight management. Med Sci Sports Exerc. 1998:30:2-10

13. Ekelund U, Luan J, Sherah LB, Esliger DW, Griew P, Cooper AR. For the international Children's accelerometry database (ICAD) collaborators: moderate to vigorous physical activity and sedentary time and cardiometabolic risk factors in children and adolescents. JAMA. 2012;307(7):704-12.

14. Saunders TJ, Gray CE, Poitras VJ, Chaput J-P, Janssen I, Katzmarzyk PT, Olds T, Connor Gorber S, Kho ME, Sampson M, et al. Combinations of physical activity, sedentary behaviour and sleep: relationships with health indicators in school-aged children and youth. Appl Physiol Nutr Metab. 2016:41(6 (Suppl 3):S283-93.

15. Chaput J-P, Dutil C. Lack of sleep as a contributor to obesity in adolescents: impacts on eating and activity behaviors. Int J Behav Nutr Phys. 2016;13(1):103.

16. Mansoubi M, Pearson N, Biddle SJH, Clemes S. The relationship between sedentary behaviour and physical activity in adults: a systematic review. Prev Med. 2014;69:28-35.

17. Pearson N, Biddle SJH, Braithwaite RE, van Sluijs EMF, Atkin AJ. Associations between sedentary behaviour and physical activity in children and adolescents: a meta-analysis. Obes Rev. 2014;15:666-75.

18. Pearson N, Biddle SJH. Sedentary behaviour and dietary intake in children, adolescents and adults: a systematic review. Am J Prev Med. 2011;41(2):178-88.

19. Hill $A B$. The environment and disease: association or causation? Proc R Soc Med. 1965;58(5):295-300

20. Lucas RM, McMichael AJ. Associaton or causation: evaluting links between "environment and disease". B World Health Organ. 2005;83(10):792-5.

21. Cooper $\mathrm{H}$, Koenka AC. The overview of reviews: unique challenges and opportunities when research syntheses are the principal elements of new integrative scholarship. Am Psychol. 2012;67(6):446-62.

22. Shea BJ, Grimshaw JM, Wells GA, Boers M, Andersson N, Hamel C, Porter AC Tugwell P, Moher D, Bouter LM. Development of AMSTAR: a measurement tool to assess the methodological quality of systematic reviews. BMC Med Res Methodol. 2007:7(1):10.

23. Cohen J. Statistical power analysis for the behavioral sciences. Hillsdale, NJ: Erlbaum; 1988

24. Rosenthal JA. Qualitative descriptors of strength of association and effect size. J Soc Serv Res. 1996:21(4):37-59.

25. Mistry SK, Puthussery S. Risk factors of overweight and obesity in childhood and adolescence in South Asian countries: a systematic review of the evidence. Public Health. 2015;129(3):200-9.

26. Prentice-Dunn H, Prentice-Dunn S. Physical activity, sedentary behavior, and childhood obesity: a review of cross-sectional studies. Psychol Health Med. 2012;17(3):255-73

27 Zhang G, Wu L, Zhou L, Lu W, Mao C. Television watching and risk of childhood obesity: a meta-analysis. Eur J Public Health. 2016;26(1):13-8.

28 Must A, Tybor DJ. Physical activity and sedentary behavior: a review of longitudinal studies of weight and adiposity in youth. Int J Obes. 2005;29 Suppl 2:S84-96.

29 Pate RR, O'Neill JR, Liese AD, Janz KF, Granberg EM, Colabianchi N, Harsha DW, Condrasky MM, O'Neil PM, Lau EY, et al. Factors associated with development of excessive fatness in children and adolescents: a review of prospective studies. Obes Rev. 2013;14(8):645-58.

30 Stierlin AS, De Lepeleere S, Cardon G, Dargent-Molina P, Hoffmann B, Murphy MH, Kennedy A, O'Donoghue G, Chastin SFM, De Craemer M. A systematic review of determinants of sedentary behaviour in youth: $\mathrm{A}$ DEDIPAC-study. Int J Behavl Nutr Phy. 2015:12(1):133.

31 Tanaka C, Reilly JJ, Huang WY. Longitudinal changes in objectively measured sedentary behaviour and their relationship with adiposity in children and adolescents: systematic review and evidence appraisal. Obes Rev. 2014;15(10):791-803.

32 van Ekris E, Altenburg TM, Singh AS, Proper Kl, Heymans MW, Chinapaw MJM. An evidence-update on the prospective relationship between childhood sedentary behaviour and biomedical health indicators: a systematic review and meta-analysis. Obes Rev. 2016;17(9):833-49.

33 Carson V. Hunter S, Kuzik N, Gray CE, Poitras VJ, Chaput JP, Saunders TJ, Katzmarzyk PT, Okely AD, Connor Gorber S, et al. Systematic review of sedentary behaviour and health indicators in school-aged children and youth: an update. Appl Physiol Nutr Metab. 2016;41(6 Suppl 3):S240-65.

34 Cliff DP, Hesketh KD, Vella SA, Hinkley T, Tsiros MD, Ridgers ND, Carver A, Veitch J, Parrish AM, Hardy LL, et al. Objectively measured sedentary behaviour and health and development in children and adolescents: systematic review and meta-analysis. Obes Rev. 2016;17(4):330-44.

35 Costigan SA, Barnett L, Plotnikoff RC, Lubans DR. The health indicators associated with screen-based sedentary behavior among adolescent girls: a systematic review. J Adolesc Health. 2013;52(4):382-92.

36 Fletcher E, Leech R, McNaughton SA, Dunstan DW, Lacy KE, Salmon J. Is the relationship between sedentary behaviour and cardiometabolic health in adolescents independent of dietary intake? a systematic review. Obes Rev. 2015:16(9):795-805.

37 Fröberg A, Raustorp A. Objectively measured sedentary behaviour and cardio-metabolic risk in youth: a review of evidence. Eur J Pediatr. 2014; 173(7):845-60

38 Gorely T, Marshall SJ, Biddle SJH. Couch kids: correlates of television viewing among youth. Int J Behav Med. 2004;11:152-63.

39 Leech RM, McNaughton SA, Timperio A. The clustering of diet, physical activity and sedentary behavior in children and adolescents: a review. Int J Behavl Nutr Phy. 2014:11:4

40 Mitchell JA, Byun W. Sedentary behavior and health outcomes in children and adolescents. Am J Lifestyle Med. 2014;8(3):173-99.

41 Rey-López JP, Vicente-Rodríguez G, Biosca M, Moreno LA. Sedentary behaviour and obesity development in children and adolescents. Nutr Metab Cardiovasc. 2008;18(3):242-51.

42 Stierlin A, De Lepeleere S, Cardon G, Dargent-Molina P, Hoffmann B, Murphy M, Kennedy A, O'Donoghue G, Chastin S, De Craemer M, et al. A systematic review of determinants of sedentary behaviour in youth: a DEDIPAC-study. Int J Behav Nutr Phys. 2015;12(1):133.

43 Azevedo LB, Ling J, Soos I, Robalino S, Ells L. The effectiveness of sedentary behaviour interventions for reducing body mass index in children and adolescents: systematic review and meta-analysis. Obes Rev. 2016;17(7):62335.

44 Bautista-Castano I, Doreste J, Serra-Majem L. Effectiveness of interventions in the prevention of childhood obesity. Eur J Epidemiol. 2004;19(7):617-22.

45 DeMattia L, Lemont L, Meurer L. Do interventions to limit sedentary behaviours change behaviour and reduce childhood obesity? a critical review of the literature. Obes Rev. 2007;8(1):69-81.

46 Leung MM, Agaronov A, Grytsenko K, Yeh MC. Intervening to reduce sedentary behaviors and childhood obesity among school-age youth: A systematic review of randomized trials. J Obes. 2012(Article ID 685430): $1-14$

47 Liao Y, Liao J, Durand CP, Dunton GF. Which type of sedentary behaviour intervention is more effective at reducing body mass index in children? a meta-analytic review. Obes Rev. 2014;15(3):159-68.

48 Luckner H, Moss JR, Gericke CA. Effectiveness of interventions to promote healthy weight in general populations of children and adults: a metaanalysis. Eur J Public Health. 2012;22(4):491-7.

49 Ramsey Buchanan L, Rooks-Peck CR, Finnie RKC, Wethington HR, Jacob V, Fulton JE, Johnson DB, Kahwati LC, Pratt CA, Ramirez G, et al. Reducing recreational sedentary screen time: a community guide systematic review. Am J Prev Med. 2016;50(3):402-15.

50 Stice $\mathrm{E}$, Shaw $\mathrm{H}$, Marti CN. A meta-analytic review of obesity prevention programs for children and adolescents: the skinny on interventions that work. Psychol Bull. 2006;132(5):667-91.

51 Wahi G, Parkin PC, Beyene J, Uleryk EM, Birken CS. Effectiveness of interventions aimed at reducing screen time in children: a systematic review and meta-analysis of randomized controlled trials. Arch Pediatr Adolesc Med. 2011;165(11):979-86.

52 Wu L, Sun S, He Y, Jiang B. The effect of interventions targeting screen time reduction: a systematic review and meta-analysis. Medicine. 2016;95(27):e4029.

53 Mansoubi M, Pearson N, Clemes SA, Biddle SJH, Bodicoat DH, Tolfrey K, Edwardson CL, Yates T. Energy expenditure during common sitting and standing tasks: examining the $1.5 \mathrm{MET}$ definition of sedentary behaviour. BMC Public Health. 2015;15:516.

54 Braithwaite I, Stewart AW, Hancox RJ, Beasley R, Murphy R, Mitchell EA. The Isaac phase three study group: the worldwide association between television viewing and obesity in children and adolescents: cross sectional study. PLoS ONE. 2013;8(9):e74263. 
55 Hancox RJ, Poulton R. Watching television is associated with childhood obesity: but is it clinically important? Int J Obes. 2005;30(1):171-5.

56 Ness AR, Leary SD, Mattocks C, Blair SN, Reilly JJ, Wells J, Ingle S, Tilling K, Davey Smith G, Riddoch C. Objectively measured physical activity and fat mass in a large cohort of children. PLoS Med. 2007;4(3):e97. doi:10.1371/ journal.pmed.0040097.

57 Thorp AA, Owen N, Neuhaus M, Dunstan DW. Sedentary behaviors and subsequent health outcomes in adults: a systematic review of longitudinal studies, 1996-2011. Am J Prev Med. 2011;41(2):207-15.

58 Biddle SJH, Pearson N, Ross GM, Braithwaite R. Tracking of sedentary behaviours of young people: a systematic review. Prev Med. 2010;51:345-51.

59 Pedisic Z. Measurement issues and poor adjustments for physical activity and sleep undermine sedentary behaviour research - The focus should shift to the balance between sleep, sedentary behaviour, standing and activity. Kinesiology. 2014;46(1):135-46.

60 Strasburger VC, Wilson BJ, Jordan AB. Children, adolescents, and the media. 2nd ed. Los Angeles, CA: Sage; 2009.

61 Tremblay MS, LeBlanc AG, Kho ME, Saunders TJ, Larouche R, Colley RC, Goldfield G, Conor Gorber S. Systematic review of sedentary behaviour and health indicators in school-aged children and youth. Int J Behavl Nutr Phy. 2011;8(1):98

\section{Submit your next manuscript to BioMed Central} and we will help you at every step:

- We accept pre-submission inquiries

- Our selector tool helps you to find the most relevant journal

- We provide round the clock customer support

- Convenient online submission

- Thorough peer review

- Inclusion in PubMed and all major indexing services

- Maximum visibility for your research

Submit your manuscript at www.biomedcentral.com/submit 